\title{
Psychotherapy and medication management strategies for obsessive-compulsive disorder
}

This article was published in the following Dove Press journal:

Neuropsychiatric Disease and Treatment

22 August 201I

Number of times this article has been viewed

\author{
Kelda HWalsh \\ Christopher J McDougle \\ Department of Psychiatry, Indiana \\ University School of Medicine, \\ Indianapolis, IN, USA
}

\begin{abstract}
Obsessive-compulsive disorder (OCD) is a chronic anxiety disorder. While medication and psychotherapy advances have been very helpful to patients, many patients do not respond adequately to initial trials of serotonergic medication or cognitive-behavioral therapy (CBT) and require multiple treatment trials or combination therapies. Comorbidity may also influence treatment response. The role of streptococcal infections in pediatric OCD has become an area of intense scrutiny and controversy. In this article, current treatment methods for OCD will be reviewed, with special attention to strategies for treating OCD in children and in patients with comorbid tic disorders. Alternative psychotherapy strategies for patients who are highly anxious about starting CBT, such as cognitive therapy or augmentation with D-cycloserine, will be reviewed. Newer issues regarding use of antibiotics, neuroleptics, and glutamate modulators in OCD treatment will also be explored.
\end{abstract}

Keywords: OCD, exposure/response prevention therapy, PANDAS, tic disorder

\section{Introduction}

Obsessive-compulsive disorder (OCD) is a chronic, often disabling anxiety disorder featuring obsessions or compulsions or, most typically, both of these. ${ }^{1}$ This common condition has a lifetime prevalence of $1.6 \%-2.3 \% .^{2,3}$ Onset peaks in the early $20 \mathrm{~s}$, but a smaller early-onset peak in preadolescence, much more common in boys than girls, may be associated with tic comorbidity. ${ }^{3-5}$ Children are more likely to present with compulsions alone, or to have brief compulsions atypical of adult OCD, such as blinking or breathing rituals. ${ }^{6}$

This paper will focus on the two major treatment strategies for OCD: cognitivebehavioral therapy (CBT) and serotonergic medications. Indicators of quality treatment will be reviewed, with particular attention to the care of pediatric patients. Because of the high rate of treatment-resistance in OCD, some novel strategies such as cognitive therapy (CT) (which de-emphasizes exposure) and medication augmentation with neuroleptics or glutamate (GLU) modulators will also be explored.

\section{Comorbidity and pediatric autoimmune neuropsychiatric disorders after streptococcus}

Comorbidity with other psychiatric conditions is reported in $79.7 \%$ of patients with OCD and may impact treatment response. ${ }^{7}$ In adult OCD, comorbid major depression is seen in $54 \%$ of patients; anxiety disorders and alcohol-use disorders are also 
common. ${ }^{3}$ In pediatric OCD, comorbidity with attentiondeficit/hyperactivity disorder (ADHD) (34\%-51\%) and tics or tic disorders $(20 \%-80 \%)$ is also common. ${ }^{8,9}$

Over the last 15 years, controversy has arisen over the possible association of prepubertal-onset OCD with streptococcal pharyngitis, known as pediatric autoimmune neuropsychiatric disorders after streptococcus (PANDAS). ${ }^{10,11}$ PANDAS is modeled on Sydenham's chorea, a streptococcustriggered autoimmune disease characterized by abrupt onset of chorea, which is treated with antibiotic prophylaxis. ${ }^{12}$ PANDAS, it is theorized, results when the body mounts an immune response against streptococcal infection but the antibodies attack the basal ganglia in error, triggering brain dysfunction. Swedo et $\mathrm{l}^{13}$ have proposed PANDAS criteria of (a) abrupt prepubertal onset of OCD and/or tics; (b) significant impairment within 48 hours of symptom onset; (c) associated chorea or hyperactivity; and (d) temporal association of exacerbations with at least two streptococcal infections. Positive streptococcal titers and cultures are very frequent in children during regional streptococcal outbreaks, triggering the requirement for two infection-associated exacerbations.

Parents of children with OCD may find the highly publicized theory of PANDAS accessible and compelling. It is easy to see why families may take comfort in the idea that the pediatrician could treat their child with an antibiotic instead of the child requiring specialty care from a mental health care provider. However, the theory remains controversial. A thorough search for evidence of autoimmune markers in twelve children with PANDAS found no correlation. ${ }^{14}$ Two prospective studies, both lasting 2 years, investigated association of streptococcal infections with tic and OCD symptoms in children diagnosed with PANDAS. One study found that new infection predicted a modest symptom increase, ${ }^{15}$ while the other found only $12.5 \%$ of symptom exacerbations were linked to infections in the previous 4 weeks. ${ }^{16}$

Proper treatment of children with PANDAS is debated. Gabbay et al ${ }^{17}$ expressed concerns that $82 \%$ of patients diagnosed with PANDAS by community pediatricians had no laboratory evidence of any group A beta-hemolytic streptococcal infections and were being treated inappropriately with antibiotics. The efficacy of such antibiotic prophylaxis of PANDAS remains suspect following publication of two antibiotic prophylaxis studies. ${ }^{18-20}$ Current expert consensus guidelines recommend that children with PANDAS be treated with antibiotics only during acute streptococcal infections and that they be treated for OCD concomitantly with standard OCD medication and psychotherapy. ${ }^{10,21}$

\section{Treatment strategies: exposure and response prevention therapy}

Controlled studies of OCD treatment have focused on exposure and response prevention (ERP) therapy and on serotonergic medications. Studies typically use the gold-standard structured clinician rating instrument, the Yale-Brown Obsessive-Compulsive Scale (Y-BOCS), or the Children's Y-BOCS (CY-BOCS), to monitor response. ${ }^{22,23}$ Y-BOCS/ CY-BOCS scores range from 0 to 40 , with a score of 17 or higher considered clinically significant. Significant treatment response is typically defined as reduction in Y-BOCS/CYBOCS score by at least $25 \%-35 \%$.

ERP therapy is the preferred form of psychotherapy for OCD, particularly for patients with milder symptoms and minimal comorbidity. ERP therapy is recommended as a first-line treatment for adults with OCD who are able to complete the treatment protocol or who prefer not to take medications,${ }^{24}$ however, patients with significant comorbid depression or anxiety may find ERP therapy difficult. ERP therapy is also preferred as the first-line treatment for children and adolescents, particularly those patients with milder symptom severity (ie, CY-BOCS score $<19$ ) and minimal comorbidity. ${ }^{25,26}$ Pediatric patients with comorbid major depression or disruptive behavior disorders such as ADHD or oppositional defiant disorder may be less responsive to ERP therapy. Sexual or religious obsessions may be less responsive to ERP therapy than other obsession types in children; tic comorbidity has demonstrated variable impact on ERP therapy response in pediatric studies. ${ }^{27}$

ERP therapy, a specialized form of CBT, has a mean effect size of 1.13 in adults and 1.45 in children. ${ }^{26,28}$ Approximately 55\% of patients completing 10-20 sessions of ERP therapy report substantial improvement. ${ }^{29}$ ERP therapy has demonstrated efficacy in multiple controlled studies for adults $\mathrm{s}^{30-34}$ and children. ${ }^{35-37}$ The combination of exposure to feared situations and prevention of ritualization has been found superior to the components of ERP only. ${ }^{38}$

Due to a shortage of well-trained, experienced providers, high-quality ERP therapy may be difficult for many patients to access. Blanco et $\mathrm{al}^{39}$ estimated that less than $10 \%$ of OCD patients receive adequate ERP therapy. Quality ERP therapy features prolonged, graded, personalized exposure to avoided stimuli, such as sources of contamination for patients obsessed with germs. The patient and the provider develop a hierarchy of feared situations, starting with exposure to moderately feared situations, and targeting highly feared situations midway through treatment, to allow time to work through more difficult exposures. ${ }^{40}$ Quality exposure 
sessions last at least 90 minutes and feature strict response prevention during and between sessions. ${ }^{41}$ Better-quality therapy is provided by experienced ERP therapists, who may use manualized protocols, including "How I ran OCD off my land" for pediatric patients. ${ }^{42}$

Pediatric ERP therapy has demonstrated efficacy in multiple controlled studies, with positive results maintained for up to 24 months of follow-up. ${ }^{36}$ Positive results have even been reported for 31 children, aged from 5 to 8 years, participating in a controlled study comparing family ERP therapy with family relaxation therapy. ${ }^{43} \mathrm{March}^{44}$ emphasizes taking great care in obtaining the child's input regarding design of the exposure sessions, as "what appears to be graded exposure to the therapist may turn out to be flooding for the child." ${ }^{4}$ Pediatric ERP therapy often includes extinction, or the removal of parents' positive reinforcement of OCD symptoms (ie, providing reassurance when the child is anxious, or even aiding in ritual completion each morning so that the family is not late for work and school). Extinction may be more effective if the child helps design the extinction plan. New forms of positive reinforcement, such as prizes and reward ceremonies, are built into the ERP therapy for children.

\section{ERP therapy formats: visit frequency, individual, group, and family sessions}

Typical ERP therapy is delivered in 15-20 weekly or twice weekly sessions. Patients travelling from out of town may prefer intensive treatment (eg, 12 hours of therapy delivered in 5 days) although some patients may worry this model is too intense or brief. ${ }^{45}$ Storch et al, ${ }^{27}$ in a study of 56 patients, found intensive daily CBT was as effective as weekly sessions.

Group therapy is less expensive for patients than individual sessions. Group therapy may be especially helpful for socially isolated patients, particularly hoarders, and it has shown similar efficacy to individual sessions. ${ }^{46}$

Family ERP therapy may be especially helpful in targeting family accommodation of OCD symptoms, reported in 70\% of families. ${ }^{47}$ In a study of 65 families, daily reassurance was provided by $56 \%$ of families; daily participation in rituals, associated with greater symptom severity, was seen in $46 \%{ }^{48}$ Significant reduction of family accommodation is associated with better treatment outcome. ${ }^{47}$ In a pilot group family ERP therapy study, high parental involvement in exposure homework improved outcome. ${ }^{49}$ Parents participating in family ERP therapy act as coaches between therapist-assisted exposures, they target accommodations at home, and they work on their own distress associated with their child's exposure practice. ${ }^{43}$ Two long-term follow-up studies of family ERP therapy have demonstrated that the majority of patients maintained significant symptom reduction for at least 18 months following the therapy. ${ }^{36,50}$

CT has been investigated as an alternative to ERP therapy. $\mathrm{CT}$ is focused on altering dysfunctional beliefs about intrusive thoughts. These thoughts are seen in $90 \%$ of the normal population $^{51}$ but OCD patients misinterpret these thoughts as "having serious implications, for which the person having the thoughts could be personally responsible." ${ }^{52}$ CT for OCD emphasizes cognitive strategies over exposure; however, it has been criticized for not being a "pure" form of CT in that many CT studies include some exposure. Some patients may find CT less anxiety provoking and more palatable because it de-emphasizes exposure. ${ }^{53}$ In direct comparisons, ERP therapy has outperformed $\mathrm{CT} .{ }^{40}$

\section{Hoarding}

Hoarding is a controversial symptom in OCD research. Hoarding may be neurobiologically distinct from other forms of OCD, with some researchers proposing classifying hoarding separately from OCD in the Diagnostic and Statistical Manual of Mental Disorder (5th edition), as "compulsive hoarding." 54 Genetic studies suggest that hoarding is common and highly heritable, particularly in women. ${ }^{55}$ While hoarding symptoms are reported by a substantial minority of patients with OCD, populations of patients with significant hoarding symptoms who lack other OCD symptoms have been identified. ${ }^{56}$ Older women living alone are particularly likely to present for clinical care of hoarding behaviors; many may have comorbid social phobia. ${ }^{57}$ While hoarded clutter may interfere with their functioning, patients with hoarding symptoms often do not seek care and find their hoarding ego-syntonic. ${ }^{58}$ Neuroimaging studies of OCD patients with prominent hoarding symptoms have demonstrated greater activation of bilateral anterior ventromedial prefrontal cortex (VMPFC) in response to hoarding-related provocation than in nonhoarding OCD control subjects. ${ }^{59} \mathrm{VMPFC}$ lesions in humans have been reported to trigger new hoarding behaviors. ${ }^{60-62}$

Hoarding symptoms have proven less responsive to typical ERP therapy and OCD medications than other symptom clusters. ${ }^{63}$ New treatment models for hoarding symptoms feature a mixture of in-office sessions and individual home visits to deal with accumulated clutter and use saving inventories and clutter image ratings, rather than 
the Y-BOCS. ${ }^{64}$ Hoarding patients appear to have particular issues with social isolation, treatment refusal (37\% of patients in one study), and low compliance. In a manualized, wait-list controlled study, $41 \%$ of patients demonstrated significant improvement. ${ }^{63}$ Therapeutic strategies included motivational interviewing to reduce ambivalence about homework and therapy attendance. Training in organizing, decision making, and problem solving was provided, as well as exposure to decrease acquiring and increase discarding behaviors. Published manuals regarding hoarding behaviors include Buried in Treasures: Help for Compulsive Acquiring, Saving, and Hoarding (a self-help book) ${ }^{65}$ and Compulsive Hoarding and Acquiring: Therapist Guide. ${ }^{66}$

\section{Medication treatment of OCD}

The United States Food and Drug Administration (FDA) has approved serotonin reuptake inhibitors (SRIs) - including clomipramine (CMI) and the selective serotonin reuptake inhibitors (SSRIs) fluoxetine (FLX), fluvoxamine (FLV), paroxetine (PAR), and sertraline (SER) - for OCD treatment. CMI is approved for age 10 and older; FLV, age 8 and older; FLX, age 7 and older; and SER, age 6 and older. The effect size for SRIs is 0.91 for adults and 0.46 in children. ${ }^{67,68}$ While the advent of serotonergic medications has been a great boon for patients with OCD, typically 40\%-68\% of patients do not respond to the first SRI trial, and "responders" may continue to struggle with very intense symptoms and remain syndromic. ${ }^{69}$

An adequate SRI trial for OCD should last 10-12 weeks, with at least 4-6 weeks at the maximum tolerated dose. SRIs are recommended as first-line treatment for adults with severe OCD or who are not able to complete ERP therapy because of comorbidity or inability to access ERP therapy services. ${ }^{24}$ SRIs are considered first-line treatment for children and teenagers with more severe OCD (CY-BOCS score $\geq 19$ ), preferably in combination with ERP therapy.

\section{SSRIs in OCD}

SSRIs are well-established treatments for OCD and are preferred to CMI because they are less likely to be toxic in overdose, to prolong the corrected QT interval and trigger cardiac arrhythmia, or to cause seizures. Relatively high doses of several SSRIs have been required in adult studies - ie, FLX or PAR doses of at least $40 \mathrm{mg}$ and escitalopram of at least $20 \mathrm{mg} .{ }^{70-73}$ Comparison studies among SSRIs are rare, and there is a lack of convincing evidence that one SSRI is more effective than the others.
The efficacy of SSRI treatment of pediatric OCD is well established, although there have been more intense safety concerns regarding antidepressants in the younger population. The FDA issued a black-box warning regarding elevated risk of suicidal ideation or attempts in patients under the age of 25 years treated with antidepressants, following review of 24 placebo-controlled studies. No completed suicides were reported. ${ }^{74,75}$ While the OCD studies, unlike depression studies, did not reveal increased risk of suicidal ideation or behavior in the SSRI-treated children and teenagers, suicidal ideation in a 13 -year-old with comorbid major depression triggered premature discontinuation of an early FLX study. ${ }^{76,77}$

\section{CMI in OCD}

CMI was the first medication to demonstrate OCD efficacy. In multiple meta-analyses of adult medication trials, it has demonstrated superior efficacy to SSRIs. ${ }^{69,78-80}$ This superiority also holds true in pediatric meta-analyses, with an effect size of 0.85 as compared with 0.46 for all SRIs (SSRIs plus CMI). ${ }^{26,68}$ Patients treated with CMI should have electrocardiogram and blood levels checked regularly and should be aware of the risk of orthostatic hypotension, seizures, and urinary retention. Because of these side effects, CMI is typically reserved for patients who have not responded adequately to at least two SSRI trials. In a controlled pediatric CMI study, the maximum dose was $3 \mathrm{mg} / \mathrm{kg}$, or $200 \mathrm{mg}$ daily, in 10- to 17 -year-olds. ${ }^{81}$

Intravenous (IV) CMI has been studied in adults, on an investigational basis, typically in inpatients with severe OCD not responsive to multiple prior medication trials, including oral CMI. ${ }^{82-84}$ IV CMI may be better tolerated than the oral form and it provides 4- to 14-fold higher peak plasma concentrations. ${ }^{83}$ Response rates in this highly refractory population have been low; for instance, in one placebocontrolled study of 46 patients, $21 \%$ of treated patients versus $0 \%$ of controls were responders after 2 weeks of daily infusions, with $58 \%$ maintaining responder status on oral CMI 1 month later. ${ }^{85}$

\section{Tic comorbidity and SRI treatment}

Tic comorbidity has been a particular concern in pediatric OCD studies. In a pediatric PAR study, $75 \%$ of patients without comorbidity were responders (at least 25\% CY-BOCS score reduction); however, response rate fell to $56 \%$ for patients with comorbid ADHD and to $53 \%$ for patients with a tic disorder. ${ }^{86}$ In the large-scale controlled Pediatric Obsessive-Compulsive 
Disorder Treatment Study (POTS), while SER was more effective than placebo for patients without tics, SER did not differentiate from placebo for 17 patients with comorbid chronic tic disorders. ${ }^{35,87}$ Tic comorbidity has been reported to reduce response to FLV but not to CMI. ${ }^{88,89}$

\section{Serotonin-norepinephrine reuptake inhibitors}

The efficacy of CMI, a serotonergic tricyclic antidepressant with both serotonergic and noradrenergic action, has triggered interest in the serotonin-norepinephrine reuptake inhibitors (SNRIs) as anti-OCD medications, particularly venlafaxine (VEN). SNRIs lack CMI's antagonism of alpha1 -adrenergic, cholinergic, and histaminergic receptors, and thus are less likely to trigger orthostatic hypotension, dry mouth, and urinary retention. ${ }^{90}$ In a small adult comparator study, VEN showed similar efficacy to CMI, and was better tolerated..$^{91}$ In the only placebo-controlled VEN trial at a target dose of $225 \mathrm{mg}$ daily in adults, a trend toward improvement was noted at 8 weeks, a short duration for an OCD trial. Progress was measured using the Clinical Global Impression scale only, not the Y-BOCS. ${ }^{92}$ One hundred and thirty-four patients completed a large study comparing VEN with PAR. ${ }^{93}$ Y-BOCS reduction was similar in the treatment arms, with a mean decrease of $7.2 \pm 7.5$ points with VEN and $7.8 \pm 5.4$ points with PAR.

Mirtazapine and duloxetine have each demonstrated efficacy in small open studies. ${ }^{90,94}$

\section{SRI augmentation strategies}

Medication augmentation strategies are useful for patients who are treatment resistant, typically defined as those who have not responded adequately to at least two SSRI trials and to CMI. The most promising medication classes for SRI augmentation are the neuroleptics and GLU modulators.

\section{Neuroleptic augmentation in OCD}

When second-generation antipsychotics were developed, it was hoped that their combined serotonergic and dopaminergic effects might prove useful as OCD monotherapy. However, second-generation neuroleptic monotherapy has not been effective for OCD and may even cause OCD-like symptoms in previously unaffected patients with schizophrenia. ${ }^{95-98}$ In one study, schizophrenic patients developing obsessivecompulsive symptoms on clozapine had higher clozapine and norclozapine blood levels than patients not developing those symptoms. ${ }^{97}$
Neuroleptic augmentation increases metabolism in key brain areas implicated in OCD. In a functional neuroimaging study, 15 patients with OCD who had not responded to two SRI trials were randomized to risperidone (RIS) or placebo augmentation. Patients treated with RIS demonstrated increased metabolic rates in the striatum, cingulate gyrus, prefrontal cortex, and thalamus. Those patients with low metabolic rates in the striatum before RIS augmentation were likely to respond favorably to RIS. ${ }^{99}$

RIS, a second-generation antipsychotic, and haloperidol (HAL), a first-generation antipsychotic, were the bestperforming neuroleptics in Bloch et al's ${ }^{100}$ meta-analysis of OCD augmentation agents. In this analysis of nine doubleblind, placebo-controlled trials of HAL, RIS, quetiapine, and olanzapine, patients with comorbid tics were especially likely to respond to augmentation. In the meta-analysis, onethird of patients not responding to two SRI trials became responders with neuroleptic addition. In the sole HAL study, patients with tics responded to a mean dose of $6.2 \pm 3 \mathrm{mg}$ daily. ${ }^{101}$ Three positive RIS augmentation studies used doses ranging from 0.5 to $3 \mathrm{mg}$ for most patients. ${ }^{102-104}$ Data were inconclusive for quetiapine and olanzapine augmentation. Quetiapine is the most studied neuroleptic in OCDs, with four controlled studies, only one of which demonstrated clinical significance. ${ }^{100,105}$

Response to neuroleptic augmentation is much quicker than response to a SRI alone; most patients demonstrate response within 4 weeks. While long-term studies of neuroleptic augmentation have not been published, long-term maintenance of the neuroleptic appears necessary, as relapse was seen in 15 of 18 patients discontinuing neuroleptic augmentation in a chart review and was particularly likely in the first 2 months following discontinuation. ${ }^{106}$ The risks and benefits should be considered carefully by patients and providers due to the risks of weight gain, dyslipidemia, diabetes, and tardive dyskinesia.

Pediatric trials of neuroleptic augmentation are limited to two case series evaluating RIS. In the larger series, four of 17 adolescents had Y-BOCS score reductions of at least $15 \% .^{107,108}$

\section{Stimulant use in OCD treatment}

Stimulant medications, particularly amphetamines, have been studied in OCD, typically as SSRI/SNRI augmentation agents. Mechanism of action of these agents in OCD is unclear, as stimulants induce compulsive rituals, ${ }^{109}$ but has been postulated to relate to pro-serotonergic effects. ${ }^{110}$ 
Patients have been reported to demonstrate OCD-symptom reduction following single stimulant doses. ${ }^{10,111}$ A doubleblind study comparing dextroamphetamine augmentation with caffeine control found $58 \%$ of patients were Y-BOCS responders to caffeine, compared with $50 \%$ of patients to dextroamphetamine. ${ }^{12}$ At this point, stimulant use in OCD would be considered investigational.

\section{GLU modulators as OCD augmentation agents}

Evidence is mounting that GLU, "the most common excitatory neurotransmitter" 113 may play an important role in the pathophysiology of OCD. A study of eleven medicationnaïve children with OCD, for instance, demonstrated that the OCD patients had higher caudate concentrations of GLU plus glutamine than normal controls on proton magnetic resonance spectroscopy. Subsequent PAR treatment normalized GLU activity. ${ }^{114}$

Medications modulating GLU have been marketed as treatments for amyotrophic lateral sclerosis (riluzole [RIL]), Alzheimer's disease (memantine [MEM]), and seizure disorders (topiramate, lamotrigine). Clinical OCD studies have focused on using GLU modulators as SRI augmentation agents. One such agent, RIL, reduces GLU release and blocks gamma-aminobutyric acid reuptake. RIL triggers hepatic transaminase elevations in at least $50 \%$ of patients, and $2 \%$ demonstrate transaminase elevations to five times normal levels, a trigger to RIL withdrawal in amyotrophic lateral sclerosis studies. ${ }^{115}$

RIL has been studied in two adult case series totaling 26 patients. Transient transaminase increases in a small number of patients did not necessitate study withdrawal, occurring as late as 20 weeks after RIL initiation. Approximately half of the patients demonstrated at least a 35\% Y-BOCS score reduction, including some patients with hoarding symptoms. Significant reductions in Hamilton Depression Rating Scale and Hamilton Anxiety Scale scores were also reported. ${ }^{115,116}$

In an open-label pediatric OCD trial, 100-200 mg daily of RIL was added to stable anti-OCD medications for 12 weeks. RIL was well tolerated by the six youths with a mean age of 14.4 years and mean CY-BOCS reduction was 39\%. ${ }^{117}$ This trial was so promising that it inspired a 12-week controlled pediatric RIL trial that is ongoing at the National Institute of Mental Health (NIMH) and includes patients with comorbid autism spectrum disorders. Final data for this study have not been published. However, two of the NIMH patients have developed pancreatitis, one of whom had unusually high RIL blood levels, which might have related to the recent addition of FLV. Another child with premorbid liver steatosis was withdrawn due to transaminase elevation. ${ }^{118}$

MEM is a noncompetitive N-methyl-D-aspartate GLU receptor antagonist that limits GLU neurotoxicity. Unlike RIL, MEM lacks hepatotoxicity. In a 12-week open-label study, adults stable on a SRI for at least 12 weeks were treated with adjunctive MEM titrated from $5 \mathrm{mg}$ daily to $10 \mathrm{mg}$ twice daily by week 4 . Six of eleven study completers had Y-BOCS reductions of at least 25\%; reduction in depression ratings was not correlated with Y-BOCS reduction. ${ }^{119}$

Topiramate has also shown promise as an OCD augmentation agent in two open-label adult case series of 26 patients combined; no patients developed renal stones. ${ }^{120,121}$ Mean dose ranged from 237.5 to $253.1 \mathrm{mg} /$ day. However, topiramate has also been reported to trigger de novo OCD symptoms in two patients, one of whom cleared promptly with topiramate cessation. ${ }^{122}$ The other was a 19-year-old who required citalopram treatment following topiramate withdrawal. ${ }^{123}$ Lamotrigine at $100 \mathrm{mg}$ daily for 4 weeks was effective for only one of four patients in another open-label case series. ${ }^{124}$

\section{Benefits of combination therapy (ERP therapy plus medication)}

A small number of placebo-controlled trials have explored the relative efficacy of SRIs, ERP therapy, or their combination. ERP therapy and combination therapy have proven superior to SRIs in child and adult populations. In adults, Foa et $\mathrm{al}^{33}$ compared combination therapy, CMI therapy (to a maximum of $250 \mathrm{mg}$ daily), and ERP therapy in 86 patients. While all treatments were superior to placebo, ERP therapy and combination therapy were equivalent, and both were superior to CMI only. In the pediatric POTS study, SER (to a maximum of $200 \mathrm{mg}$ daily) was compared with ERP therapy and combination therapy. ${ }^{35}$ In total, 112 youths completed the study. Combination therapy was superior at one of two sites to ERP therapy only, ERP therapy was superior to SER at both sites, and SER was superior to placebo. The authors concluded that youths with OCD should begin treatment with ERP therapy only or with ERP therapy plus a SSRI.

Medication pretreatment has also been explored as a way to make patients less anxious about ERP therapy, as at least $25 \%$ of patients seeking therapy have been reported to decline participation once offered. ${ }^{29,125}$ D-cycloserine (DCS), an N-methyl-D-aspartate receptor partial agonist, is being investigated for this role. Dosage administered and time of dose before session has varied among studies; 
Rothbaum ${ }^{126}$ recently suggested that lower doses (ie, $100-125 \mathrm{mg}$ ) administered close to the start of the session may be helpful, as at higher doses, DCS acts as a full glycine site antagonist and has been found to exacerbate symptoms of schizophrenia. ${ }^{127}$

DCS has not been helpful in all studies and appears more likely to reduce early patient fear ratings or speed up the "slope of recovery" in early sessions than to enhance ultimate symptom reduction. ${ }^{128-131}$

\section{Surgical treatment for treatment- resistant OCD}

For patients with severe and highly treatment-resistant OCD, two surgical methods are available that have demonstrated efficacy for some patients not responding to medication and psychotherapy. The less invasive option is deep brain stimulation of the anterior limb of the internal capsule or the adjacent striatum. ${ }^{132}$ The more invasive treatment of last resort is ventral capsular/ventral striatal capsulotomy. ${ }^{133}$

\section{Conclusion}

ERP therapy is the first-line treatment for most patients with OCD, although lack of availability of high-quality services limits its use. SSRIs used at adequate doses for at least 10-12 weeks are reasonable first options for patients unable to complete or obtain ERP therapy. Patients not responsive to first rounds of monotherapy may benefit from the combination of ERP therapy and a SSRI. CMI is an appropriate option for patients who do not respond to two adequate SSRI trials, but it requires close monitoring due to the risk of seizures and cardiac toxicity. Neuroleptic augmentation of SRIs is a reasonable option for some treatment-resistant patients, especially those with tics. While GLU modulators are promising, controlled trials in children and adults are needed before their role in OCD therapy is clear. Patients whose significant anxiety prevents them from initiating ERP therapy may benefit from DCS treatment early in ERP therapy or from $\mathrm{CT}$; however, these methods also warrant further research.

\section{Disclosure}

The authors report no conflicts of interest in this work.

\section{References}

1. Murray CJL, Lopez AD. Global Burden of Disease. Vol 1. Boston, MA: World Health Organization; 1996.

2. Kessler RC, Chiu WT, Demler O, Merikargas KR, Walters EE. Prevalence, severity, and comorbidity of 12-month DSM-IV disorders in the National Comorbidity Survey Replication. Arch Gen Psychiatry. 2005;62(6):617-627.
3. Ruscio AM, Stein DJ, Chiu WT, Kessler RC. The epidemiology of obsessive-compulsive disorder in the National Comorbidity Survey Replication. Mol Psychiatry. 2010;15:53-63.

4. Karno M, Golding JM, Sorenson SB, Burnam MA. The epidemiology of obsessive-compulsive disorder in five US communities. Arch Gen Psychiatry. 1988;45:1094-1099.

5. Castle DJ, Deale A, Marks IM. Gender differences in obsessive compulsive disorder. Aust N Z J Psychiatry. 1995;29:114-117.

6. Rettew DC, Swedo SE, Leonard HL, Lenane MC, Rapoport JL. Obsessions and compulsions across time in 79 children and adolescents with obsessive-compulsive disorder. J Acad Child Adolesc Psychiatry. 1992;31:1050-1056

7. Crino R, Slade T, Andrews G. The changing prevalence and severity of obsessive-compulsive disorder criteria from DSM-III to DSM-IV. Am J Psychiatry. 2005;162:876-882.

8. Fireman B, Koran LM, Leventhal JL, Jacobson A. The prevalence of clinically recognized obsessive-compulsive disorder in a large health maintenance organization. Am J Psychiatry. 2001;158:1904-1910.

9. Geller DA. Obsessive-compulsive and spectrum disorders in children and adolescents. Psychiatr Clin North Am. 2006;29:353-370.

10. Swedo SE, Leonard HL, Rapoport JL. The pediatric autoimmune neuropsychiatric disorders associated with streptococcal infection (PANDAS) subgroup: separating fact from fiction. Pediatrics. 2004; 113:907-911.

11. Kurlan R, Kaplan EL. The pediatric autoimmune neuropsychiatric disorders associated with streptococcal infection (PANDAS) etiology for tics and obsessive-compulsive symptoms: hypothesis or entity? Practical considerations for the clinician. Pediatrics. 2004;113:883-886.

12. Gerber MA, Baltimore RS, Eaton CB, et al. Prevention of rheumatic fever and diagnosis and treatment of acute Streptococcal pharyngitis. Circulation. 2009;119:1541-1551.

13. Swedo SE, Leonard HL, Garvey MA, et al. Pediatric autoimmune neuropsychiatric disorders associated with streptococcal infections: clinical description of the first 50 cases. Am J Psychiatry. 1998;155: 264-271.

14. Singer HS, Gause C, Morris C, Lopez P; for Tourette Syndrome Study Group. Serial immune markers do not correlate with clinical exacerbations in pediatric autoimmune neuropsychiatric disorders associated with streptococcal infections. Pediatrics. 2008;121:1198-1205.

15. Lin H, Williams KA, Katsovich L, et al. Streptococcal upper respiratory tract infections and psychosocial stress predict future tic and obsessive-compulsive symptom severity in child and adolescents with Tourette syndrome and obsessive-compulsive disorder. Biol Psychiatry. 2010:67:684-691.

16. Kurlan R, Johnson D, Kaplan EL. Streptococcal infection and exacerbations of childhood tics and obsessive-compulsive symptoms: a prospective blinded cohort study. Pediatrics. 2008;121:1188-1197.

17. Gabbay V, Coffey BJ, Babb JS, et al. Pediatric autoimmune neuropsychiatric disorders associated with streptococcus: comparison of diagnosis and treatment in the community and at a specialty clinic. Pediatrics. 2008;122:273-278.

18. Garvey MA, Perlmutter SJ, Allen AJ, et al. A pilot study of penicillin prophylaxis for neuropsychiatric exacerbations triggered by streptococcal infections. Biol Psychiatry. 1994;45:1564-1571.

19. Snider LA, Lougee L, Slattery M, Grant P, Swedo SE. Antibiotic prophylaxis with azithromycin or penicillin for childhood-onset neuropsychiatric disorders. Biol Psychiatry. 2005;57:788-792.

20. Budman C, Coffey B, Dure L, et al. Regarding "antibiotic prophylaxis with azithromycin or penicillin for childhood-onset neuropsychiatric disorders." Biol Psychiatry. 2005;58:917.

21. King RA, Leonard H, March J; for Work Group on Quality Issues. Practice parameters for the assessment and treatment of children and adolescents with obsessive-compulsive disorder. $J$ Am Acad Child Adolesc Psychiatry. 1998;37 Suppl 10:27S-45S.

22. Goodman WK, Price LH, Rasmussen SA, et al. The Yale-Brown Obsessive Compulsive Scale, II: validity. Arch Gen Psychiatry. 1989; 46:1012-1016. 
23. Scahill L, Riddle MA, McSwiggin-Hardin M, et al. Children's Yale-Brown Obsessive Compulsive Scale: reliability and validity. J Am Acad Child Adolesc Psychiatry. 1997;36:844-852.

24. Koran LM, Hanna GL, Hollander E, Nestadt G, Simpson HB; for American Psychiatric Association. Practice guideline for the treatment of patients with obsessive-compulsive disorder. Am J Psychiatry. 2007; 164:7-54.

25. March JS, Frances A, Kahn D, Carpenter D. The Expert Consensus Guideline Series: treatment of obsessive-compulsive disorder. J Clin Psychiatry. 1997;58 Suppl 4:1-72.

26. Watson HJ, Rees CS. Meta-analysis of randomized, controlled treatment trials for pediatric obsessive-compulsive disorder. J Child Psychol Psychiatry. 2008;49:489-498.

27. Storch EA, Merlo LJ, Larson MJ, et al. Clinical features associated with treatment-resistant pediatric obsessive-compulsive disorder. Compr Psychiatry. 2008;49:35-42.

28. Rosa-Alcazar AI, Sanchez-Meca J, Gomez-Conesa A, MartinMartinez F. Psychological treatment of obsessive-compulsive disorder: a meta-analysis. Clin Psychol Rev. 2008;28:1310-1325.

29. Jenike MA. Treating obsessive-compulsive disorder. Harv Ment Health Lett. 2009;25:4-5.

30. Fals-Stewart W, Marks A, Schafer J. A comparison of behavioral group therapy and individual behavior therapy in treating obsessivecompulsive disorder. J Nerv Ment Dis. 1993;181:189-193.

31. Lindsay M, Crino R, Andrews G. Controlled trial of exposure and response prevention in obsessive-compulsive disorder. Br J Psychiatry. 1997;171:135-139.

32. Van Balkom AJ, De Haan E, Van Oppen P, Spinhoven P, Hoogduin KA, van Dyck R. Cognitive and behavioral therapies alone versus in combination with fluvoxamine in the treatment of obsessive-compulsive disorders. J Nerv Ment Dis. 1998;186:492-499.

33. Foa EB, Liebowitz MR, Kozak MJ, et al. Randomized, placebocontrolled trial of exposure and ritual prevention, clomipramine, and their combination in the treatment of obsessive-compulsive disorder. Am J Psychiatry. 2005;162:151-161.

34. Nakatani E, Nakagawa A, Nakao T, et al. A randomized trial of Japanese patients with obsessive-compulsive disorder: effectiveness of behavior therapy and fluvoxamine. Psychother Psychosom. 2005;74: 269-276.

35. Pediatric OCD Treatment Study (POTS) Team. Cognitive-behavior therapy, sertraline, and their combination for children and adolescents with obsessive-compulsive disorder: the Pediatric OCD Treatment Study (POTS) randomized controlled trial. JAMA. 2004;292:1969-1976.

36. Barrett P, Healy-Farrell L, March JS. Cognitive-behavioral family treatment of childhood obsessive-compulsive disorder: a controlled clinical trial. J Am Acad Child Adolesc Psychiatry. 2004;43:46-62.

37. DeHaan E, Hoogduin KAL, Buitelaar JK, Keijsers GPJ. Behavior therapy versus clomipramine for the treatment of obsessive-compulsive disorder in children and adolescents. $J$ Am Acad Child Adolesc Psychiatry. 1998;37:1022-1029.

38. Foa E, Steketee G, Grayson J, et al. Deliberate exposure and blocking of obsessive-compulsive rituals: immediate and long-term effects. Behav Res Ther. 1984;15:450-472.

39. Blanco C, Offson M, Stein DJ, Simpson HB, Gameroff MJ, Narrow WH. Treatment of obsessive-compulsive disorders by US psychiatrists. J Clin Psychiatry. 2006;67:946-951.

40. Abramowitz JS. The psychological treatment of obsessive-compulsive disorder. Can J Psychiatry. 2006;51:407-416.

41. Fisher PL, Wells A. How effective are cognitive and behavioral treatments for obsessive compulsive disorder? A clinical significance analysis. Behav Res Ther. 2005;43:1543-1558.

42. March JS, Mulle K. OCD in Children and Adolescents: A CognitiveBehavioral Treatment Manual. New York: Guilford Press; 1998.

43. Freeman JB, Garcia AM, Covne L, et al. Early childhood OCD: preliminary findings from a family-based cognitive-behavioral approach. J Am Acad Child Adolesc Psychiatry. 2008;47:593-602.
44. March JS. Cognitive-behavioral psychotherapy for children and adolescents with OCD: a review and recommendations for treatment. J Am Acad Child Adolesc Psychiatry. 1995;34:7-18.

45. Bevan A, Oldfield VB, Salkovskis PM. A qualitative study of the acceptability of an intensive format for the delivery of cognitivebehavioural therapy for obsessive-compulsive disorder. $\mathrm{Br} J \mathrm{Clin}$ Psychol. 2010;49:173-191.

46. Jaurrieta N, Jimenez-Murcia S, Alonso P, et al. Individual versus group cognitive behavioral treatment for obsessive-compulsive disorder: follow up. Psychiatry Clin Neurosci. 2008;62:697-704.

47. Merlo LJ, Lekmkuhl HD, Geffken GR, Storch EA. Decreased family accommodation associated with improved therapy outcome in pediatric obsessive-compulsive disorder. J Consult Clin Psychol. 2009;77: 355-360.

48. Peris TS, Bergman L, Langley A, Chang S, McCracken JT, Piacentini J. Correlates of accommodation of pediatric obsessive-compulsive disorder: parent, child, and family characteristics. J Am Acad Child Adolesc Psychiatry. 2008;47:1173-1181.

49. Martin JL, Margo T. Group cognitive-behavior therapy with family involvement for middle-school-aged children with obsessivecompulsive disorder: a pilot study. Child Psychiatry Hum Dev. 2005;36: 113-127.

50. O'Leary EMM, Barrett P, Fjermestad KW. Cognitive-behavioral family treatment for childhood obsessive-compulsive disorder: a 7-year follow-up study. J Anxiety Disord. 2009;23:973-978.

51. Rachman S, De Silva P. Abnormal and normal obsessions. Behav Res Ther. 1978;16:233-248

52. Neziroglu F, Henricksen J, Yaryura-Tobias JA. Psychotherapy of obsessive-compulsive disorder and spectrum: established facts and advances 1995-2005. Psychiatr Clin North Am. 2006;29:585-604.

53. Whittal ML, Thordarson DS, McLean PD. Treatment of obsessivecompulsive disorder: cognitive behavior therapy vs exposure and response prevention. Behav Res Ther. 2005;42:1559-1576.

54. Mataix-Cols D, Frost RO, Pertusa A, et al. Hoarding disorder: a new diagnosis for DSM-V? Depress Anxiety. 2010;27:556-572.

55. Iervolino AC, Perroud N, Fullana MA, et al. Prevalence and heritability of compulsive hoarding: a twin study. Am J Psychiatry. 2009;166: $1156-1161$.

56. Rasmussen SA, Eisen JL. The epidemiology and clinical features of obsessive-compulsive disorders. Psychiatr Clin North Am. 1992;15: 743-758.

57. Pertusa A, Fullana MA, Singh S, et al. Compulsive hoarding: OCD symptom, distinct clinical syndrome, or both? Am J Psychiatry. 2008; 165:1289-1298

58. Rachman S, Elliott CM, Shafran R, Radomsky AS. Separating hoarding from OCD. Behav Res Ther. 2009;47:520-522.

59. An SK, Mataix-Cols D, Lawrence NS, et al. To discard or not to discard: the neural basis of hoarding symptoms in obsessive-compulsive disorder. Mol Psychiatry. 2009;14:318-331.

60. Anderson SW, Bechara A, Damasio J, Tranel D, Damasio AR. Impairment of social and moral behavior related to early damage in the human prefrontal cortex. Nat Neurosci. 1999;2:1032-1037.

61. Cohen L, Angladette L, Benoit N, Pierrot-Deseilligny C. A man who borrowed cars. Lancet. 1999;353:34.

62. Hahm DS, Kang Y, Cheong SS, Na DL. A compulsive collecting behavior following an A-com aneurysm rupture. Neurology. 2001;56: 398-400.

63. Steketee G, Frost RO, Tolin DE, Rasmussen J, Brown TA. Waitlistcontrolled trial of cognitive behavior therapy for hoarding disorder. Depress Anxiety. 2010;27:476-484.

64. Muroff J, Steketee G, Rasmussen J, et al. Group cognitive and behavioral treatment for compulsive hoarding: a preliminary trial. Depress Anxiety. 2009;26:634-640.

65. Tolin DF, Frost RO, Steketee G. Buried in Treasures: Help for Compulsive Acquiring, Saving, and Hoarding. New York: Oxford University Press; 2007. 
66. Steketee G, Frost RO. Compulsive Hoarding and Acquiring: Therapist Guide. New York: Oxford University Press; 2007.

67. Eddy KT, Dutra L, Bradley R, Westen D. A multidimensional meta-analysis of psychotherapy and pharmacotherapy for obsessive-compulsive disorder. Clin Psychol Rev. 2004;24:1011-1030.

68. Geller DA, Biederman J, Stewart SE, et al. Which SSRI? A meta-analysis of pharmacotherapy trials in pediatric obsessive-compulsive disorder. Am J Psychiatry. 2003;160:1919-1928.

69. Ackerman DL, Greenland S. Multivariate meta-analysis of controlled drug studies for obsessive-compulsive disorder. JClin Psychopharmacol. 2002;22:309-317.

70. Bloch MH, McGuire J, Landeros-Weisenberger A, Leckman JF, Pittenger C. Meta-analysis of the dose-response relationship of SSRI in obsessive-compulsive disorder. Mol Psychiatry. 2010;15:850-855.

71. Montgomery SA, McIntyre A, Osterheider M, et al. A double-blind placebocontrolled study of fluoxetine in patients with DSM-III-R obsessivecompulsive disorder. Eur Neuropsychopharmacol. 1993;3:143-152.

72. Hollander E, Allen A, Steiner M, et al. Acute and long-term treatment and prevention of relapse of obsessive-compulsive disorder with paroxetine. J Clin Psychiatry. 2003a;64:1113-1121.

73. Stein DJ, Andersen EW, Tonnoir B, Fineberg N. Escitalopram in obsessive-compulsive disorder: a randomized, placebo-controlled, paroxetine-referenced, fixed-dose, 24-week study. Curr Med Res Opin. 2007;23:701-711.

74. Vasa RA, Carlino AR, Pine DS. Pharmacotherapy of depressed children and adolescents: current issues and potential directions. Biol Psychiatry. 2006;59:1021-1028.

75. March JS, Klee BJ, Kremer CM. Treatment benefit and risk of suicidality in multicenter, randomized, controlled trials of sertraline in children and adolescents. J Child Adolesc Psychopharmacol. 2006;16:91-102.

76. Bridge JA, Ivengar S, Salary CB, et al. Clinical response and risk for reported suicidal ideation and suicide attempts in pediatric antidepressant treatment: a meta-analysis of randomized controlled trials. JAMA. 2007;297:1683-1696.

77. Riddle MA, Scahill L, King RA, et al. Double-blind, crossover trial of fluoxetine and placebo in children and adolescents with obsessive-compulsive disorder. J Am Acad Child Adolesc Psychiatry. 1992;31:1062-1069.

78. Abramowitz J. Effectiveness of psychological and pharmacological treatments for obsessive-compulsive disorder: a quantitative review. J Consult Clin Psychol. 1997;65:44-52.

79. Greist JH, Jefferson JW, Kobak KA, Katzelnick DJ, Serlin RC. Efficacy and tolerability of serotonin transport inhibitors in obsessive-compulsive disorder: a meta-analysis. Arch Gen Psychiatry. 1995;52:53-60.

80. Kobak KA, Greist JH, Jefferson JW, Katzelnick DJ, Henk HJ. Behavioral versus pharmacological treatments of obsessive compulsive disorder: a meta-analysis. Psychopharmacology (Berl). 1998;136:205-216.

81. DeVeaugh-Geiss J, Moroz G, Biederman J, et al. Clomipramine hydrochloride in childhood and adolescent obsessive-compulsive disorder: a multicenter trial. JAm Acad Child Adolesc Psychiatry. 1992;31:45-49.

82. Cordioli AV, de Sousa MB, Bochi DB. Intravenous clomipramine in severe and refractory obsessive-compulsive disorder. $J$ Clin Psychopharmacol. 2003;23:665-666.

83. Koran LM, Sallee FR, Pallanti S. Rapid benefit of intravenous pulse loading of clomipramine in obsessive-compulsive disorder. $\mathrm{Am}$ J Psychiatry. 1997;154:396-401.

84. Koran LM, Aboujaoude E, Ward H, et al. Pulse-loaded intravenous clomipramine in treatment-resistant obsessive-compulsive disorder. J Clin Psychopharmacol. 2006;26:79-83.

85. Fallon BA, Liebowitz MR, Campeas R, et al. Intravenous clomipramine for obsessive-compulsive disorder refractory to oral clomipramine. Arch Gen Psychiatry. 1998;55:918-924.

86. Geller DA, Biederman J, Stewart SE, et al. Impact of comorbidity on treatment response to paroxetine in pediatric obsessive-compulsive disorder: is the use of exclusion criteria empirically supported in randomized clinical trials? J Child Adolesc Psychopharmacol. 2003; 13 Suppl 1:S19-S29.
87. March JS, Franklin ME, Leonard H, et al. Tics moderate treatment outcome with sertraline but not cognitive-behavior therapy in pediatric obsessive-compulsive disorder. Biol Psychiatry. 2007;61:344-347.

88. McDougle CJ, Goodman WK, Leckman JF, Barr LC, Heninger GR, Price LH. The efficacy of fluvoxamine in obsessive-compulsive disorder: effects of comorbid chronic tic disorder. J Clin Psychopharmacol. 1993;13:354-358.

89. Miguel EC, Shavitt RG, Ferrao YA, Brotto SA, Diniz JB. How to treat OCD in patients with Tourette syndrome. J Psychosom Res. 2003; 55:49-57.

90. Dell'osso B, Mundo E, Marazziti D, Altamura AC. Switching from serotonin reuptake inhibitors to duloxetine in patients with resistant obsessive-compulsive disorder: a case series. J Psychopharmacol. 2008;22:210-213.

91. Albert U, Aguglia E, Maina G, Bogetto F. Venlafaxine versus clomipramine in the treatment of obsessive-compulsive disorder: a preliminary, single-blind, 12-week, controlled study. J Clin Psychiatry. 2002;63:1004-1009.

92. Yaryura-Tobias JA, Neziroglu FA. Venlafaxine in obsessive-compulsive disorder. Arch Gen Psychiatry. 1996;53:653-654.

93. Denys D, van de Wee N, van Megen HJGM, et al. A double blind comparison of venlafaxine and paroxetine in obsessive-compulsive disorder. J Clin Psychopharmacol. 2003;23:568-575.

94. Koran LM, Quirk T, Lorberbaum JP, Elliott M. Mirtazapine treatment of obsessive-compulsive disorder. J Clin Psychopharmacol. 2001; 21:537-539.

95. McDougle CJ, Barr LC, Goodman WK, et al. Lack of efficacy of clozapine monotherapy in refractory obsessive-compulsive disorder. Am J Psychiatry. 1995;152:1812-1814.

96. Lykouras L, Alevizos B, Michalopoulou P, Rabavilas A. Obsessivecompulsive symptoms induced by atypical antipsychotics: a review of the reported cases. Prog Neuropsychopharmacol Biol Psychiatry. 2003;27:333-346.

97. Lin S-K, Su S-F, Pan C-H. Higher plasma drug concentration in clozapine-treated schizophrenic patients with side effects of obsessivecompulsive symptoms. Ther Drug Monit. 2006;28:303-307.

98. Sareen J, Kirshner A, Lander M, Kjernisted KD, Eleff MK, Reiss JP. Do antipsychotics ameliorate or exacerbate obsessive-compulsive disorder symptoms? A systematic review. J Affect Disord. 2004; 82:167-174.

99. Buchsbaum MS, Hollander E, Pallanti S, et al. Positron-emission tomography imaging of risperidone augmentation in serotonin reuptake inhibitory-refractory patients. Neuropsychobiology. 2006;53: 157-168.

100. Bloch MH, Landeros-Weisenberger A, Kelmendi B, Coric V, Bracken MG, Leckman JF. A systematic review: antipsychotic augmentation with treatment refractory obsessive-compulsive disorder. Mol Psychiatry. 2006;11:622-632.

101. McDougle CJ, Goodman WK, Leckman JF, Lee NC, Heninger GR, Price LH. Haloperidol addition in fluvoxamine-refractory obsessivecompulsive disorder: a double-blind, placebo-controlled study in patients with and without tics. Arch Gen Psychiatry. 1994;51:302-308.

102. Erzegovesi S, Guglielimo E, Siliprandi F, Bellodi L. Low-dose risperidone augmentation of fluvoxamine treatment in obsessive-compulsive disorder: a double-blind, placebo-controlled study. Eur Neuropsychopharmacol. 2005;15:69-74.

103. Hollander E, Rossi NB, Sood E, Pallanti S. Risperidone augmentation in treatment-resistant obsessive-compulsive disorder: a double-blind, placebo-controlled study. Int Clin Psychopharmacol. 2003b;6:397-401.

104. McDougle CJ, Epperson CN, Pelton GH, Wasylink S, Price LH A double-blind, placebo-controlled study of risperidone addition in serotonin reuptake inhibitor-refractory obsessive-compulsive disorder. Arch Gen Psychiatry. 2000;57:794-801.

105. Kordon A, Wahl K, Koch N, et al. Quetiapine addition to serotonin reuptake inhibitors in patients with severe obsessive compulsive disorder: a double-blind, randomized, placebo-controlled study. J Clin Psychopharmacol. 2008;28:550-554. 
106. Maina G, Albert U, Ziero S, Bogetto F. Antipsychotic augmentation for treatment resistant obsessive-compulsive disorder: what if antipsychotic is discontinued? Int Clin Psychopharmacol. 2003;1: 23-28.

107. Fitzgerald KD, Stewart CM, Tawile V, Rosenberg DR. Risperidone augmentation of serotonin reuptake inhibitor treatment of pediatric obsessive-compulsive disorder. J Child Adolesc Psychopharmacol. 1999;9:115-123.

108. Thomsen PH. Risperidone augmentation in the treatment of severe adolescent OCD in SSRI-refractory cases: a case series. Ann Clin Psychiatry. 2004;16:201-207.

109. Borcherding BG, Keysor CS, Rapoport JL, Elia J, Amass J. Motor/ vocal tics and compulsive behaviors on stimulant drugs: is there a common vulnerability? Psychiatry Res. 1190;33:83-94.

110. Joffe RT, Swinson RP, Levitt AJ. Acute psychostimulant challenge in primary obsessive-compulsive disorder. J Clin Psychopharmacol. 1991;11:237-241.

111. Woolley JB, Heyman I. Dextroamphetamine for obsessive-compulsive disorder. Am J Psychiatry. 160;1:183.

112. Koran LM, Aboujaoude E, Gamel NN. Double-blind study of dextroamphetamine versus caffeine augmentation for treatmentresistant obsessive-compulsive disorder. J Clin Psychiatry. 2009;70: $1530-1535$.

113. Pittenger C, Coric V, Banasr M, Bloch M, Krystal JH, Sanacora G. Riluzole in the treatment of mood and anxiety disorders. CNS Drugs. 2008;22:761-786.

114. Rosenberg DR, MacMaster FP, Keshavan MS, Fitzgerald KD, Stewart CM, Moore GJ. Decrease in caudate glutamatergic concentrations in pediatric obsessive-compulsive disorder patients taking paroxetine. J Am Acad Child Adolesc Psychiatry. 2000;39:1096-1103.

115. Coric V, Taskiran S, Pittenger C, et al. Riluzole augmentation in treatment-resistant obsessive-compulsive disorder: an open-label trial. Biol Psychiatry. 2005;58:424-428.

116. Pittenger C, Kelmendi B, Wasylink S, Bloch MH, Coric V. Riluzole augmentation in treatment-refractory obsessive compulsive disorder. J Clin Psychopharmacol. 2008;28(3):363-367.

117. Grant P, Lougee L, Hirschtritt M, Swedo SE. An open-label trial of riluzole, a glutamate antagonist, in children with treatment-resistant obsessive-compulsive disorder. J Child Adolesc Psychopharmacol. 2007;17:761-767.

118. Grant P, Song JY, Swedo SE. Review of the use of the glutamate antagonist riluzole in psychiatric disorders and a description of recent use in childhood obsessive-compulsive disorder. J Child Adolesc Psychopharmacol. 2010;20:309-315.
119. Aboujaoude E, Barry JJ, Gamel N. Memantine augmentation in treatment-resistant obsessive-compulsive disorder. J Clin Psychopharmacol. 2009:29:51-55.

120. Rubio G, Jimenez-Arriero MA, Martinez-Gras I, Manzanares J, Palomo T. The effects of topiramate adjunctive treatment added to antidepressants in patients with resistant obsessive-compulsive disorder. J Clin Psychopharmacol. 2006;26:341-344.

121. Van Ameringen M, Mancini C, Patterson B, Bennett M. Topiramate augmentation in treatment-resistant obsessive-compulsive disorder: a retrospective, open-label case series. Depress Anxiety. 2006;23:1-5.

122. Thuile J, Even C, Guelfi J-D. Topiramate may induce obsessivecompulsive disorder. Psychiatry Clin Neurosci. 2006;60:394.

123. Ozkara C, Ozmen M, Erdogan A, Yalug I. Topiramate-related obsessive-compulsive disorder. Eur Psychiatry. 2005;20:78-79.

124. Kumar TCR, Khanna S. Lamotrigine augmentation of serotonin re-uptake inhibitors in obsessive-compulsive disorder. Aust $\mathrm{N} \mathrm{ZJ}$ Psychiatry. 2010;34:527-528.

125. Schruers K, Koning K, Luermans J, Haack MJ, Griez E. Obsessivecompulsive disorder: a critical review of therapeutic perspectives. Acta Psychiatr Scand. 2005;111:261-271.

126. Rothbaum BO. Critical parameters for D-cycloserine enhancement of cognitive-behavioral therapy for obsessive-compulsive disorder. Am J Psychiatry. 165:293-296.

127. Shim SS, Hammonds MD, Vrabel MM. D-cycloserine augmentation for behavioral therapy. Am J Psychiatry. 2008;165:1050.

128. Storch EA, Merlo LJ, Bengston M, et al. D-cycloserine does not enhance exposure-relapse prevention therapy in obsessive-compulsive disorder. Int Clin Psychopharmacol. 2007;22:230-237.

129. Chasson GS, Buhlmann U, Tolin DF, et al. Need for speed: evaluating slopes of OCD recovery in behavior therapy enhanced with d-cycloserine. Behav Res Ther. 2010;48:675-679.

130. Kushner MG, Kim SW, Donahue C, et al. D-cycloserine augmented exposure therapy for obsessive-compulsive disorder. Biol Psychiatry. 2007;62:835-838.

131. Wilhelm S, Buhlmann U, Tolin DF, et al. Augmentation of behavior therapy with D-cycloserine for obsessive-compulsive disorder. Am J Psychiatry. 2008;165:335-341.

132. Greenberg BD, Gabriels LA, Malone DA Jr, et al. Deep brain stimulation of the ventral internal capsule/ventral striatum for obsessivecompulsive disorder: worldwide experience. Mol Psychiatry. 2010;15: 64-79.

133. Ruck C, Karlsson A, Steele JD, et al. Capsulotomy for obsessivecompulsive disorder. Arch Gen Psychiatry. 2008;65:914-922.
Neuropsychiatric Disease and Treatment

\section{Publish your work in this journal}

Neuropsychiatric Disease and Treatment is an international, peerreviewed journal of clinical therapeutics and pharmacology focusing on concise rapid reporting of clinical or pre-clinical studies on a range of neuropsychiatric and neurological disorders. This journal is indexed on PubMed Central, the 'PsycINFO' database and CAS, and is the official

\section{Dovepress}

journal of The International Neuropsychiatric Association (INA). The manuscript management system is completely online and includes a very quick and fair peer-review system, which is all easy to use. Visit http://www.dovepress.com/testimonials.php to read real quotes from published authors. 